Research Article

\title{
Similarity Law between Centrifuge Scale Test and Prototype Underwater Explosion
}

\author{
Shang Ma $\mathbb{D}^{1,2}$ Yeqing Chen, ${ }^{2}$ Zhenqing Wang $\left(\mathbb{D},{ }^{1}\right.$ Jianhui Wang, ${ }^{2}$ Linmei Lyu, ${ }^{2}$ \\ and Wanli Wei ${ }^{1,2}$ \\ ${ }^{1}$ Harbin Engineering University, Harbin, China \\ ${ }^{2}$ Institute of Defense Engineering, AMS, PLA, Beijing, China
}

Correspondence should be addressed to Zhenqing Wang; wangzhenqing@hrbeu.edu.cn

Received 26 May 2021; Revised 12 July 2021; Accepted 22 July 2021; Published 3 August 2021

Academic Editor: Piguang Wang

Copyright (c) 2021 Shang Ma et al. This is an open access article distributed under the Creative Commons Attribution License, which permits unrestricted use, distribution, and reproduction in any medium, provided the original work is properly cited.

Shock wave and bubble pulsation caused by underwater explosion destroy the hydraulic structure. However, the realization of the underwater explosion prototype test is restricted by many factors, such as the site environment. Furthermore, the repeatability of the test scheme is not strong. The centrifuge scale test provides a new way of studying the damage degree of the structure under the action of underwater explosion. The similarity relationship refers to the bridge between the scaled model and the prototype, which cannot achieve complete similarity in practice. The centrifuge-scaled model test is performed by increasing the acceleration of a certain multiple. Meanwhile, the model reduces the corresponding ratio in the geometric layout to achieve the geometric similarity with the prototype test. Therefore, the applicability of the centrifuge scaling method in the study of the dynamic response of the structure in underwater explosion needs to be explored further. In this work, the underwater explosion scaling test numerical model for $1 \mathrm{~g}$ RDX (equivalent to $1.62 \mathrm{~g}$ TNT) charge under different centrifugal acceleration conditions is established, and the calculation results of underwater pressure and dynamic response of the steel plate are compared with the centrifuge test results. A prototype model is established to study the similarity relationship between the centrifuge scale test and the prototype model when the steel plate structure is in the stage of small deformation and linear elasticity. The application of the similarity ratio in the scale test of underwater explosion the centrifuge is discussed. The application of the centrifuge in the study of the failure response of the hydraulic structure in underwater explosion is expanded by establishing the model and comparing with the experimental results.

\section{Introduction}

Underwater explosion causes very serious damage to hydraulic structures. Compared with air explosion, the power of underwater explosion is greater. The damage process of underwater explosion to the structure is mainly divided into two parts: shock wave and bubble pulsation. In 1948, Cole [1] analyzed the physical and chemical phenomena of underwater explosions, the characteristics of propagation in the impact water, and the phenomenon of bubble pulsation on the basis of a large number of experimental studies. The empirical laws of the peak pressure, propagation characteristics, and specific impulse of shock waves in underwater explosions are summarized. The corresponding calculation formulas, which are the first to systematically study the dynamic phenomena of underwater explosions, are given. Subsequently, Farley and Snay [2] obtained a wide range of far-field pressure data through experiments. Zamyshlyayev and Yakovlev $\mathrm{Yu}$ [3] modified Cole's classical theory for different application areas and expanded and refined the related research on underwater explosion. Geers and Hunter [4] proposed a Geers-Hunter underwater explosion model based on the double-asymptotic approximation method, which integrated shock wave propagation and bubble pulsation. The relationship between bubble volume acceleration and far-field pressure distribution in the shock wave stage was established, and the specific dynamic process of explosion load was further divided. Slifko [5] carried out in- 
depth experimental research on the pressure characteristics of explosive shock wave in the infinite water medium and revealed the relationship between the pressure of underwater shock wave and water depth. Aiming at the unique dynamic behavior of underwater explosion, Yao [6] and Zhang [7] investigated the dynamic behavior of bubbles under different boundary conditions. The large-equivalent charge test for underwater explosions is restricted by environmental factors. Researchers generally use small-equivalent charge tests to study the typical dynamic behavior of underwater explosions. Hung and Hwangfu [8] studied the behavior of underwater explosion bubbles at different boundaries through experiments. They used $1.12 \mathrm{~g}$ of TNT for testing and found that compared with the bubbles formed by electric sparks, those formed by underwater microcharge explosions contract slightly faster. In addition, in terms of experiments, to explore the dynamic and complex behavior of underwater explosions, researchers [9-11] used the centrifuge scale model test to study the behavior characteristics of the underwater explosion process based on the reduction ratio.

The centrifuge generates centrifugal force through highspeed rotation so that the model has a gravity field environment similar to that of the prototype. The centrifuge has always been an effective tool for simulating the blasting action effectively. Snay [12] emphasized that, in the underwater explosion scale test, the Coriolis force caused by the rotation of the centrifuge had a negligible effect on bubble movement. Price et al. [13] used a centrifuge test equipment to conduct underwater explosion tests under the action of a small structure and an additional acceleration of $190 \mathrm{~g}$; they also replicated the conditions required for the response of the prototype large-scale structure. $\mathrm{Hu}$ et al. [9] used the centrifuge scale model to study the impact factors of underwater explosions and conducted a series of studies using the centrifuge scale experiments of underwater explosion bubble pulsation. Long et al. [10] conducted a centrifuge scale-down test of the dynamic response of a steel plate structure in an underwater explosion. The experiment confirmed that the shock wave is slightly affected by the centrifuge speed, and the deformation of the steel plate structure caused by bubble pulsation could not be ignored. Song et al. [11] conducted numerical simulation on the scale test of the underwater explosion of the centrifuge and discussed the applicability of the scale to the dynamic load of the underwater explosion. Wang et al. [14] studied the law of underwater explosion shock wave and bubble pulsation under the additional acceleration of the centrifuge through the centrifuge scale model test and numerical simulation; they also analyzed the influence of the water equation of state and boundary conditions on the numerical simulation results. The use of grid size as the charge radius in the threedimensional model is recommended. Based on the similarity rate, Wang et al. [15] presented similar requirements for small-scale underwater explosion tests and explored the distribution of explosion energy in shallow water and the factors that affect the peak pressure of shock waves.

The dynamic response analysis of the structure subjected to water involves many problems, such as fluid-solid coupling.
Wang et al. [16-18] established a hydraulic concrete dynamic response structural model that considered the interaction between the structure and the surrounding environment and explored the fluid-solid coupling problem of the dynamic response of the structure. In addition, numerical simulation provides a wealth of supplementary methods for the study of underwater explosions. Blake and Gibson [19], Klaseboer et al. [20], Liu et al. [21], Pearson et al. [22], and others used the boundary element method to study nonspherical bubbles. Cui et al. [23] studied the movement of bubbles under the action of gravity and different boundary conditions through a small amount of underwater explosion experiments. Xiao et al. [24] improved the compressible nonspherical bubble dynamics model and explored the influence of bubble initial conditions in the free field and gravitational field on bubble dynamics. Liu et al. [25] used numerical calculations and indirect mapping methods to study the similarities, differences, and relationships between spherical and cylindrical charges in underwater explosions and verified them through experiments. Ming et al. [26] used the SPH method to study the shock wave load characteristics near the underwater explosive charge and proposed a SPH-FEM method to study the dynamic nonlinear behavior of ship structures under the action of underwater explosions. Liu et al. [27] used the finite element method to study the underwater explosion in the free field. Hai and Ren [28] studied the damage of reinforced concrete slabs under the action of underwater explosions through numerical simulation.

However, for the dynamic response of hydraulic structures in underwater explosions, the applicability of the centrifuge scale model remains to be studied. This paper establishes a numerical model for the scale-down test of the underwater explosion of the centrifuge, analyzes the water pressure in the underwater explosion test of the centrifuge and the dynamic response of the steel plate structure, and verifies the reliability of the model by comparing the test results with the numerical simulation results. Then, the corresponding prototype underwater explosion numerical model is established. Through comparison with the centrifuge scale model, the feasibility of the similarity law in studying the dynamic response of the structure under the action of underwater explosion is discussed. This paper expands the application of centrifuges in the study of the failure response of hydraulic structures in underwater explosions by establishing a model and comparing it with the test results.

\section{Overview of Underwater Explosion Test}

To further study the similarity rate of underwater explosion, this paper selects the centrifuge underwater explosion test conducted by Long [10] as a reference. In this paper, a numerical model is established according to the specific situation of the test, and the reliability of the model is verified.

\subsection{Centrifuge Scale Test of Steel Plate Subjected to Underwater} Explosion. Long et al. [10] used the LXJ-4-450 centrifuge experimental equipment of China Institute of Water Resources and Hydropower Research (IWHR) to carry out a scale-down test of underwater explosions. A water-retaining steel plate with 
a thickness of $50 \mathrm{~mm}$ and a height of $700 \mathrm{~mm}$ was used. The bottom of the steel plate is fixed with a concrete support. The front of the plate is filled with $600 \mathrm{~mm}$ deep water, and the other side is air. An observation window is set on the side of the model container, and a high-speed camera is placed to capture underwater explosion images. The burst center of the charge is $300 \mathrm{~mm}$ away from the water-retaining steel plate, and a pressure sensor is set at the distance $R=350 \mathrm{~mm}$ on the other side of the charge to record the pressure change in the measuring point with time during the test. The test setup and sensor layout are shown in Figure 1.

The working conditions used in the simulation are shown in Table 1 , where $G$ is the additional acceleration of the centrifuge, $1 \mathrm{~g}=9.80 \mathrm{~m} / \mathrm{s}^{2}, W$ is the mass of the TNT charge, $D$ is the explosion depth, $L$ is the horizontal distance between the charge center and the steel plate, $R$ is the charge center distance or the distance of the water pressure sensor, and Width and Height are the width and height of the steel plate, respectively.

2.2. Law of Similarity. In the scaling test, the reduction factor $\lambda$ is generally used to express the similarity multiple relationship between the prototype test and the scale-down model test. However, the use of the same scale factor so that all physical quantities strictly follow the similarity ratio is difficult. In the centrifuge test, physical quantities, such as atmospheric pressure and the density of the water medium, are consistent with the prototype test. The centrifuge test achieves the purpose of simulating the underwater explosion of a large mass charge with a small mass charge by changing the acceleration of gravity. When considering the similarity rate of the structure, the geometric dimensions, physical parameters, and boundary conditions of the original and model must follow a certain similar relationship. When studying the dynamic response of linear elastic and small deformation structures, the geometric dimensions of the original and model are similar according to a certain reduction factor $\lambda$. Achieving the same constraint conditions of the prototype and the model is difficult, and certain simplification is required, but it is only approximate rather than similar. At this time, the elastic modulus $E$, shear modulus $G$, density $\rho$, and other parameters that describe the characteristics of the material in the elastic range should meet the requirements of similar conditions as needed. When considering the similarity of gravity, the dynamic similarity criteria of materials in the dynamic process of underwater explosion are shown in Table 2, where M, L, and $\mathrm{T}$ are the mass, length, and time, respectively.

Large-scale underwater explosion tests are difficult to implement. Thus, this paper studies the dynamic response of the steel plate in the linear elastic phase of the centrifuge under the action of underwater explosion and then establishes a numerical model of the response of the prototype steel plate under the action of underwater explosion. It is compared with the centrifuge scale model to verify the reliability of the centrifuge scale model in studying the dynamic response of the structure subjected to underwater explosions.

\section{Establishment of Numerical Model and Selection of Material Parameters}

In this paper, LS-DYNA is used for numerical simulation research. By establishing a numerical model of underwater explosion, the application of the similarity rate in the underwater explosion problem is further explored on the basis of the numerical model verified with experimental results.

3.1. Finite Element Model. When using LS-DYNA to simulate the underwater explosion process, the prototype test and the centrifuge model test use symmetrical concentrated charges, and both use the same material parameters and state equations. To improve calculation efficiency, 1/2 symmetrical modeling is adopted, and symmetry constraints are imposed on the symmetry plane. The bubble pulsation process in the underwater explosion is greatly affected by the surrounding water pressure. In the centrifuge test, the overall acceleration of the model is applied to achieve the purpose of the scale-down test. At the same time, the water pressure in the centrifuge test will change greatly. In the centrifuge scale-down test, the atmospheric pressure remains the same as the prototype test, but the difference corresponds to the change in the water pressure distribution gradient due to increased acceleration. In the underwater explosion numerical model, a global downward acceleration ( $\left.G=n g ; 1 g=9.8 \mathrm{~m} / \mathrm{s}^{2}\right)$ is applied to the model so that the pressure in the water is distributed according to the actual conditions in the centrifuge test conditions. Table 1 shows that the underwater explosion tests studied in this paper are not shallow water explosions, and the explosion center is far from the steel plate. The air pocket formed by the underwater explosion on the water surface directly above the explosion center is found at a certain distance from the steel plate; to enable the water pressure distribution to converge, the influence of air on the water surface on the results must be reduced. Next, one must focus on observing the response of the steel plate to water, so the effect of the air domain could be ignored, and the atmospheric pressure on the water surface must be applied by means of uniform pressure. When simulating a centrifuge test, a vertical downward acceleration is applied to the overall model, and the hydrostatic pressure in the water is initialized before the charge is detonated. Wang et al. [30] studied the influence of grid size on underwater explosion shock wave propagation under different charge quantities and introduced the ratio of charge radius to grid side length as the calculation standard by analyzing the correlation between grid size and charge quantity under different charge quantities. Through analysis and comparison, when the grid size of the charge is $1 / 3$ of the charge radius, the calculation efficiency can be improved under the condition of ensuring the calculation accuracy and grid convergence. Therefore, $1 / 3$ of the charge size is selected as the unit side length to divide the Euler domain.

The test is carried out in a centrifuge. The model is surrounded by the walls of the test cabin. To reduce the impact of the environment on the simulation results, a nonreflective boundary is applied around the water medium. 


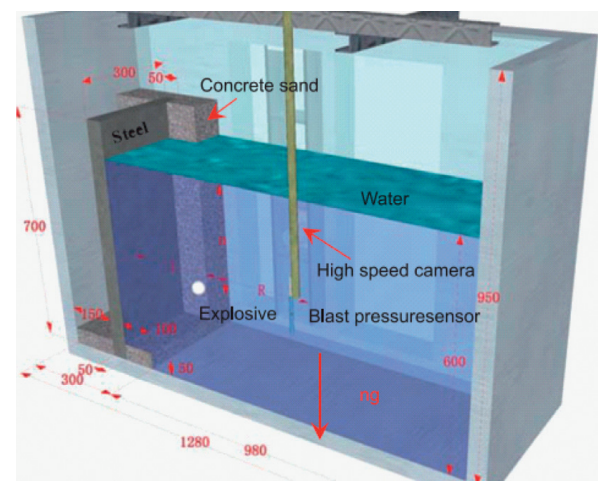

(a)

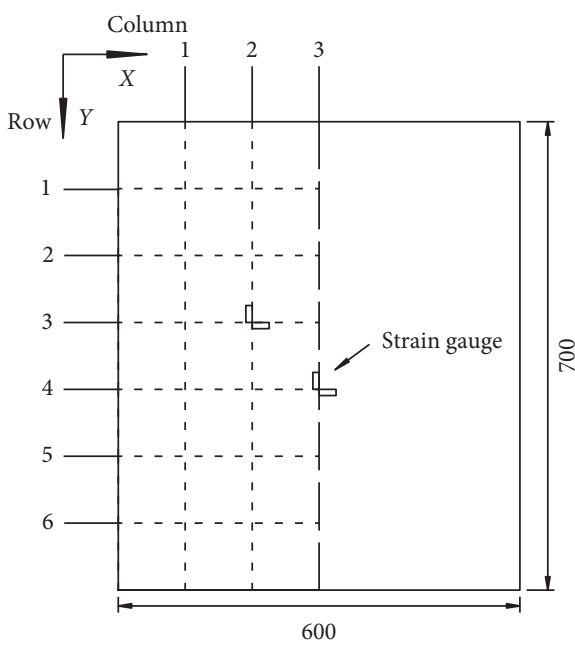

(b)

FIgURe 1: Schematic diagram of underwater explosion centrifuge test setup and sensor layout (mm). (a) Setting situation of the centrifuge test $(\mathrm{mm})[9]$. (b) Schematic diagram of the steel plate back water surface sensor layout $(\mathrm{mm})$.

Table 1: Test conditions setting details.

\begin{tabular}{|c|c|c|c|c|c|c|c|}
\hline \multirow{2}{*}{ No. } & \multirow{2}{*}{ G } & \multirow{2}{*}{$W(\mathrm{~g})$} & \multicolumn{3}{|c|}{ Position of charge in water } & \multicolumn{2}{|c|}{ Steel plate } \\
\hline & & & $D(\mathrm{~cm})$ & $L(\mathrm{~cm})$ & $R(\mathrm{~cm})$ & Width $(\mathrm{cm})$ & Height $(\mathrm{cm})$ \\
\hline UE01 & $20 \mathrm{~g}$ & 1.612 & 30 & 30 & 35 & \multirow{4}{*}{60} & \multirow{4}{*}{70} \\
\hline UE02 & $30 \mathrm{~g}$ & 1.613 & 30 & 30 & 35 & & \\
\hline UE03 & $40 \mathrm{~g}$ & 1.620 & 30 & 30 & 35 & & \\
\hline UE05 & $50 \mathrm{~g}$ & 1.640 & 30 & 30 & 35 & & \\
\hline
\end{tabular}

Surface-to-surface contact is adopted between the steel plate and the concrete support, and the contact surface can only be compressed but not tensioned. The numerical calculation model and boundary settings are shown in Figure 2.

3.2. Material Parameters. LS-DYNA provides a wealth of material models and equations of the state. This article studies the dynamics of underwater explosions. The materials involved include TNT, water, and air. In underwater explosions, high-energy explosives use *MAT_HIGH_EXPLOSIVE_BURN to simulate their material parameters and utilize the JWL equation of the state. The commonly used standard JWL state equation is

$$
P=A\left(1-\frac{\omega}{R_{1} \bar{V}}\right) e^{\left(-R_{1} \bar{V}\right)}+B\left(1-\frac{\omega}{R_{2} \bar{V}}\right) e^{\left(-R_{2} \bar{V}\right)}+\frac{\omega E}{\bar{V}}
$$

where $P$ is the pressure of the detonation product, $\bar{V}$ is the relative volume of the detonation product, and $A, B, R_{1}, R_{2}$, and $\omega$ are the parameters of the equation of the state. The material parameters of TNT are shown in Table 3.

In ls-dyna, water can use the *EOS_GRUNEISEN state equation to describe its dynamic response. When the water is under pressure, the state equation is as follows:

$$
\begin{aligned}
p= & \frac{\rho_{0} C_{0}^{2} \mu\left[1+\left(1-\gamma_{0} / 2\right) \mu-a / 2 \mu^{2}\right]}{\left[1-\left(S_{1}-1\right) \mu-S_{2} \mu^{2} / \mu+1-S_{3} \mu^{3} /(\mu+1)^{2}\right]} \\
& +\left(\gamma_{0}+a \mu\right) E_{V},
\end{aligned}
$$

where $p$ is the water pressure, $\rho_{0}$ is the initial density of the water medium, taken as $1000 \mathrm{~kg} / \mathrm{m}^{3}, C_{0}$ is the speed of sound in the water medium, degree of compression $\mu=\rho / \rho_{-} 1, E_{0}$ is the initial internal energy, internal energy increment per unit volume $E_{V}=\rho_{0}\left(E-E_{0}\right)$, and $a$ is a constant, and it is the first-order volume correction coefficient of $\gamma_{0}$, and the values are shown in Table 4.

In this paper, a three-dimensional finite element model was established, and different parameters in Table 4 were used for simulation. The test results measured by the water pressure sensor in the test UE01 were compared ( $W_{\mathrm{TNT}}=1.62 \mathrm{~g}, D=30 \mathrm{~cm}$, and $R=35 \mathrm{~cm}$ ), and the result is shown in Figure 3. As shown, the peak pressure and the wave speed are consistent with the experimental result when the coefficients recommended by Webster [32] were used. The most significant difference between Webster's model and others' model is the adoption of a higher initial acoustic velocity. With higher value of $C$, the shock wave propagates faster and attenuates slower. In fact, given that the wave speed is greater than the speed of sound in water near the 
TABLE 2: Scaling similarity relation of dynamic parameters of underwater explosion [29].

\begin{tabular}{|c|c|c|c|c|}
\hline Parameters & Dimension & Prototype & Scale model & Value \\
\hline $\begin{array}{l}\text { Explosive radius } \\
\text { Standoff distance } \\
\text { Explosion depth } \\
\text { Bubble radius } \\
\text { Length } \\
\text { Displacement }\end{array}$ & $\mathrm{L}$ & $\begin{array}{c}R_{0} \\
R \\
D \\
R_{b} \\
L \\
L\end{array}$ & $\begin{array}{c}\lambda R_{0} \\
\lambda R \\
\lambda D \\
\lambda R_{b} \\
\lambda L \\
\lambda L \\
\end{array}$ & $\begin{array}{l}\lambda \\
\lambda \\
\lambda \\
\lambda \\
\lambda \\
\lambda\end{array}$ \\
\hline Period & $\mathrm{T}$ & $T_{b}$ & $\lambda T_{b}$ & $\lambda$ \\
\hline $\begin{array}{l}\text { Explosion weight } \\
\text { Structure weight }\end{array}$ & $\mathrm{M}$ & $\begin{array}{l}W \\
M\end{array}$ & $\begin{array}{l}\lambda^{3} W \\
\lambda^{3} M\end{array}$ & $\begin{array}{l}\lambda^{3} \\
\lambda^{3} \\
\end{array}$ \\
\hline $\begin{array}{l}\text { Water density } \\
\text { Explosion density }\end{array}$ & $\mathrm{ML}^{-3}$ & $\begin{array}{l}P_{w} \\
\rho_{c}\end{array}$ & $\begin{array}{l}P_{w} \\
\rho_{c} \\
\end{array}$ & $\begin{array}{l}1 \\
1 \\
\end{array}$ \\
\hline $\begin{array}{l}\text { Fluid velocity } \\
\text { Detonation velocity }\end{array}$ & $\mathrm{LT}^{-1}$ & $\begin{array}{l}c_{w} \\
U_{c}\end{array}$ & $\begin{array}{l}c_{w} \\
U_{c}\end{array}$ & $\begin{array}{l}1 \\
1 \\
\end{array}$ \\
\hline $\begin{array}{l}\text { Atmosphere pressure } \\
\text { Shock wave peak pressure } \\
\text { Bubble pulsation pressure } \\
\text { Hydrostatic pressure } \\
\text { Strength } \\
\text { Surface load } \\
\text { Stress } \\
\text { Stress-strain relationship } \\
\end{array}$ & $\mathrm{ML}^{-1} \mathrm{~T}^{-2}$ & $\begin{array}{c}P_{\mathrm{atm}} \\
P_{m} \\
P_{b m} \\
P_{0} \\
\sigma_{\max } \\
\quad P \\
\sigma=\sigma_{\max } \\
f=\sigma(\varepsilon)\end{array}$ & $\begin{array}{c}P_{\mathrm{atm}} \\
P_{m} \\
P_{b m} \\
P_{0} \\
\sigma_{\max } \\
P \\
\sigma=\sigma_{\max } \\
f=\sigma(\varepsilon)\end{array}$ & $\begin{array}{l}1 \\
1 \\
1 \\
1 \\
1 \\
1 \\
1 \\
1\end{array}$ \\
\hline Strain & 1 & $\varepsilon$ & $\varepsilon$ & 1 \\
\hline Acceleration & $\mathrm{LT}^{-2}$ & $g$ & $g / \lambda$ & $1 / \lambda$ \\
\hline
\end{tabular}

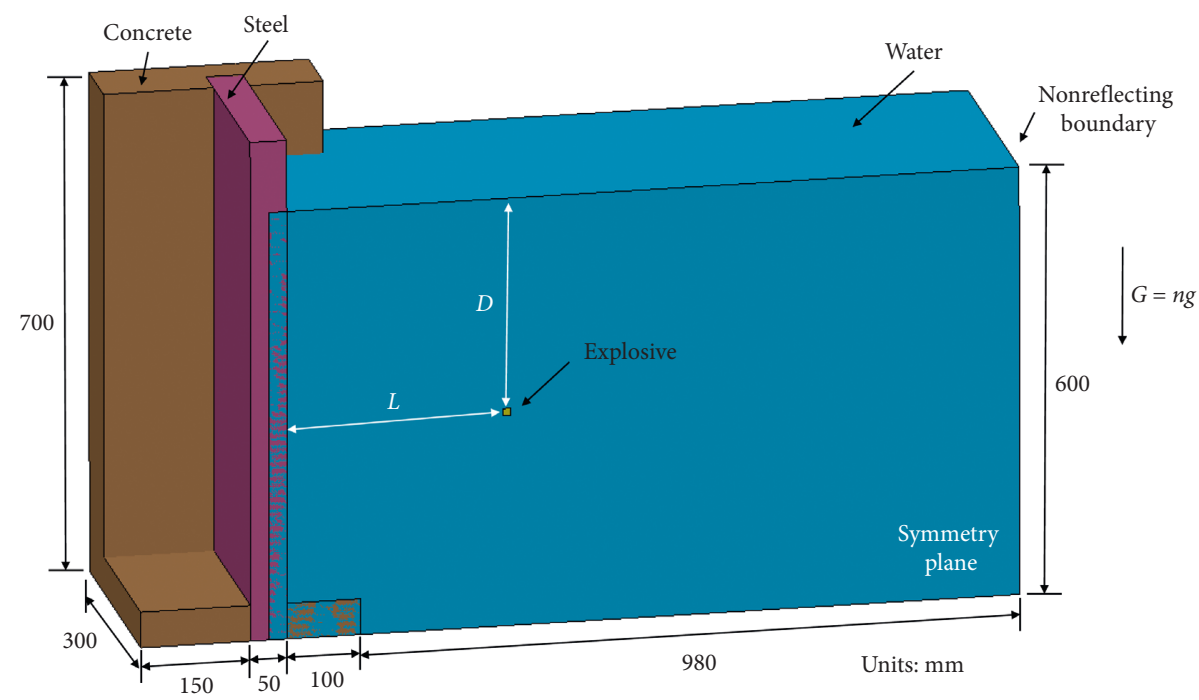

FIGURE 2: Numerical model of explosion in water.

TABLE 3: Material parameters of TNT.

\begin{tabular}{lcccccccc}
\hline$\rho /\left(\mathrm{kg} \cdot \mathrm{m}^{-3}\right)$ & \multicolumn{3}{c}{ Detonation parameter } & \multicolumn{4}{c}{ Parameter of state equation } \\
& $D_{\mathrm{CJ}}\left(\mathrm{m} \cdot \mathrm{s}^{-1}\right)$ & $P_{\mathrm{CJ}}(\mathrm{GPa})$ & $E\left(\mathrm{~J} / \mathrm{m}^{3}\right)$ & $A(\mathrm{GPa})$ & $B(\mathrm{GPa})$ & $\omega$ & $R_{1}$ & $R_{2}$ \\
\hline 1630 & 6930 & 21.0 & $6 \times 10^{9}$ & 374 & 3.23 & 0.3 & 4.15 & 0.95 \\
\hline
\end{tabular}

charge [32], Webster's model can correctly capture the pressure-density relationship of the fluid in a close proximity underwater explosion environment, which is considered in our analysis. Hai and Ren [28] also verified this point through the research results of establishing a two-dimensional model of underwater explosion. Therefore, the parameters of the equation of the state, which Webster used for water, were adopted in subsequent simulations. 
TABle 4: Parameters of the Gruneisen equation of the state for water.

\begin{tabular}{lccccc}
\hline Source & $C\left(\mathrm{~m} \cdot \mathrm{s}^{-1}\right)$ & $S_{1}$ & $S_{2}$ & $S_{3}$ & $\gamma_{0}$ \\
\hline HULL [31] & 1483 & 1.75 & 0 & 0 & 0.28 \\
SNL [31] & 1647 & 1.92 & 0 & 0 & 0 \\
Webster [32] & 2417 & 1.414 & 0 & 0 & 0 \\
\hline
\end{tabular}

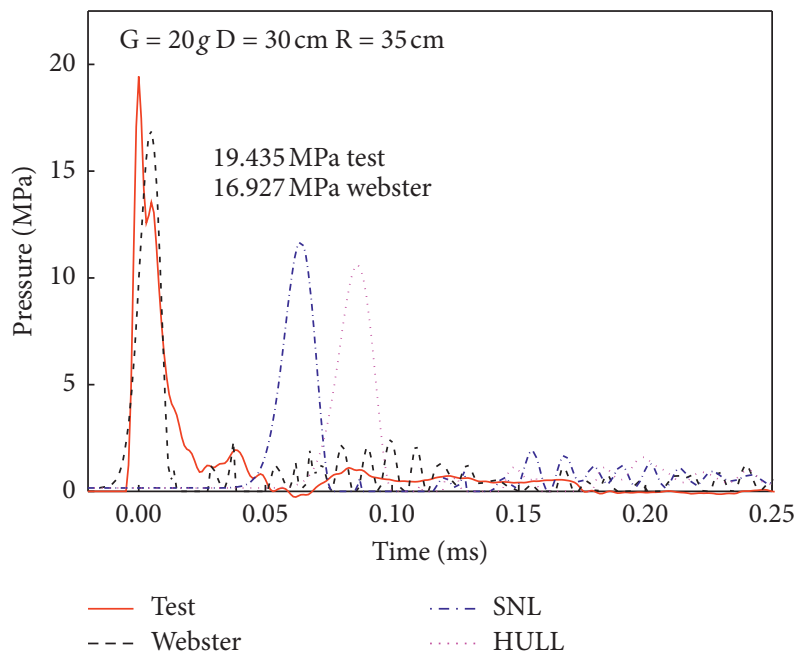

FIGURE 3: Shock wave pressure of different equations of the state for water.

The response of the steel plate in the test is in the elastic stage, the steel density is $7830 \mathrm{~kg} / \mathrm{m}^{3}$, Young's modulus is $201 \mathrm{GPa}$, and Poisson's ratio is 0.3 .

The steel plate is restrained by the concrete bearing. Similar to the steel plate, the concrete bearing is still in the elastic stage without damage in the test. However, considering that the test is still an impact dynamic test, the concrete RHT constitutive model can simulate the dynamics of concrete materials better. In the test, concrete sand M15 is selected as the bearing material. Combined with the actual situation of the test, Table 5 shows the selection of concrete material parameters. $f_{c}$ is the compressive strength of concrete, and $f_{t}$ is the tensile strength.

\section{Result Verification}

4.1. Pressure Propagation in Water. The conditions of UE01, UE02, UE03, and UE05 are the same, except for the different accelerations. The explosive depth of the charge and the explosion distance are the same. The sensor is $35 \mathrm{~cm}$ away from the explosion center. The numerical simulation results of the water pressure in these four operating conditions are compared with the test results (Figure 4).

Taking the UE03 operating condition $(G=40 \mathrm{~g})$ as an example, the detailed comparison diagram of the numerical simulation and test results of the shock wave and bubble pulsation method is shown in Figure 5.

In an underwater explosion, different accelerations have slight effects on the shock wave, and the main effect of acceleration is bubble pulsation. The bubble pulsation itself refers to the interaction between the detonation product and the surrounding water pressure. Acceleration directly affects the pressure distribution in water and has a greater impact on bubble pulsation. In Figures 4(a)-4(d), the water pressure time history curves of working conditions UE01, UE02, UE03, and UE05 under accelerations of 20, 30, 40, and $50 \mathrm{~g}$ were presented, respectively. A total of $1.0 \mathrm{~g}$ RDX charge (equivalent to $1.62 \mathrm{~g}$ TNT charge) exploded at a depth of $30 \mathrm{~cm}$ underwater, and the water pressure was measured at an explosion distance of $35 \mathrm{~cm}$ (TNT proportional explosion distance $\left.R / W^{1 / 3}=2.98 \mathrm{~m} / \mathrm{kg}^{1 / 3}\right)$. In the four working conditions, the test shock wave peak pressure is very close. Compared with the $15.26 \mathrm{MPa}$ shock wave peak pressure calculated by Cole's empirical formula, the numerical model calculation results in this paper are closer to the test results under different working conditions.

With the increase in acceleration, the period of bubble pulsation of underwater explosion is shortened, which is well proved by experiment and numerical simulation. The test was carried out in a closed water tank. In the numerical model, in order to reduce the impact of the environment on the results, the boundary was treated with no reflection, which was different from the real situation in the test and also caused the bubble pulsation obtained by the numerical simulation. The period is slightly different from the test result. However, the numerical simulation as a whole realized the whole process of underwater explosion shock wave propagation and bubble pulsation, and the second bubble pulsation phenomenon was also obtained in working conditions UE03 $(G=40 \mathrm{~g})$ and UE05 $(G=50 \mathrm{~g})$. This finding proves that the application of gravitational acceleration globally to the model can restore the dynamic process of underwater explosions with different scaling factors. 
TABLE 5: Material parameters of concrete.

\begin{tabular}{lccccc}
\hline$\rho /\left(\mathrm{kg} \cdot \mathrm{m}^{-3}\right)$ & $f_{c}(\mathrm{MPa})$ & $f_{t}(\mathrm{MPa})$ & Young's modulus $(\mathrm{GPa})$ & Failure strain & Poisson's ratio \\
\hline 2500 & 15 & 1.5 & 27.6 & 0.01 & 0.15 \\
\hline
\end{tabular}

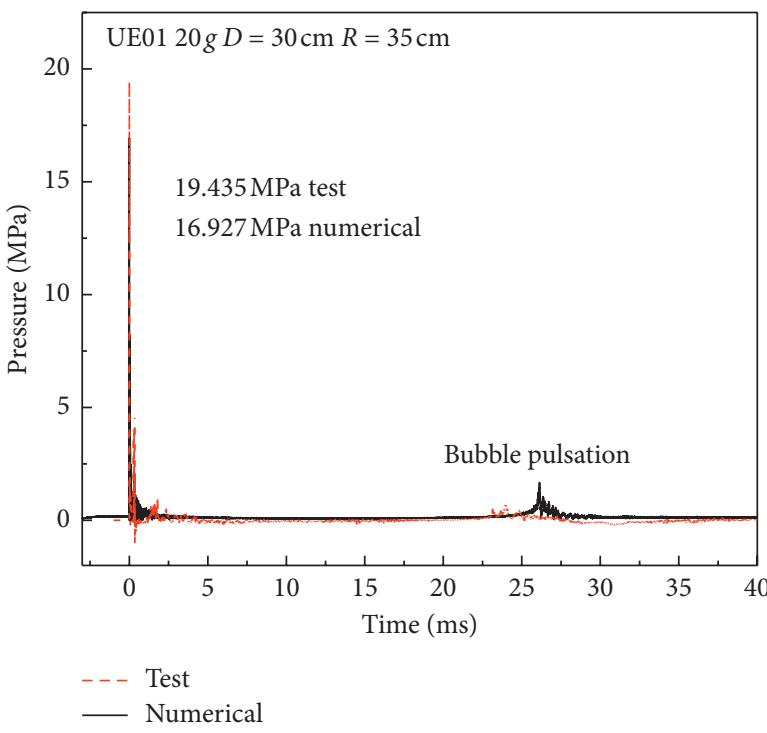

(a)

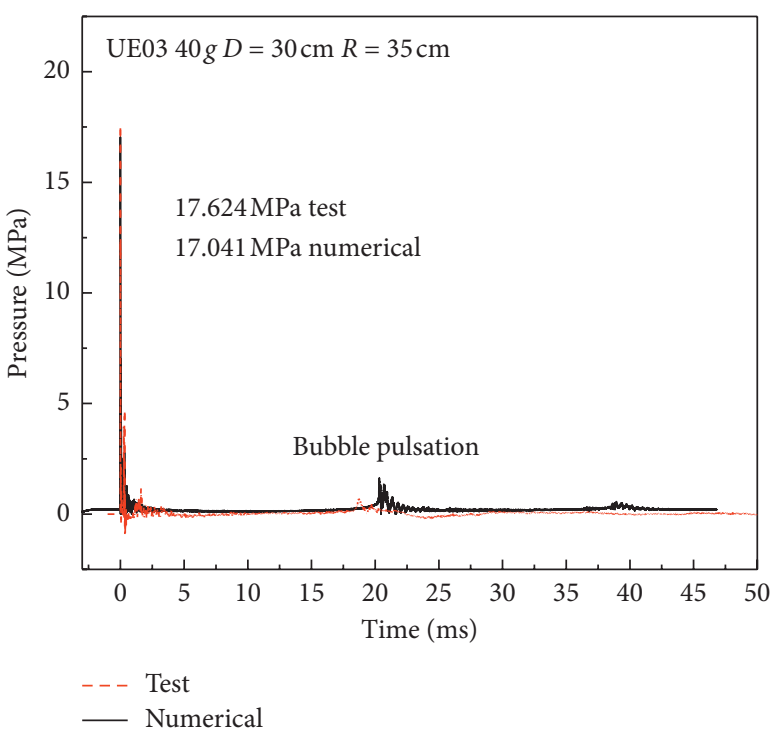

(c)

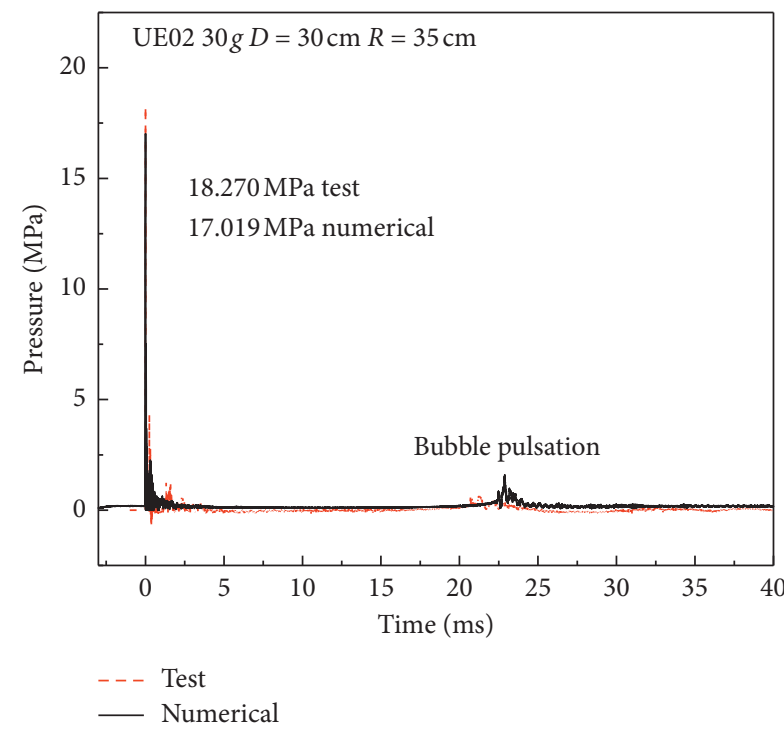

(b)

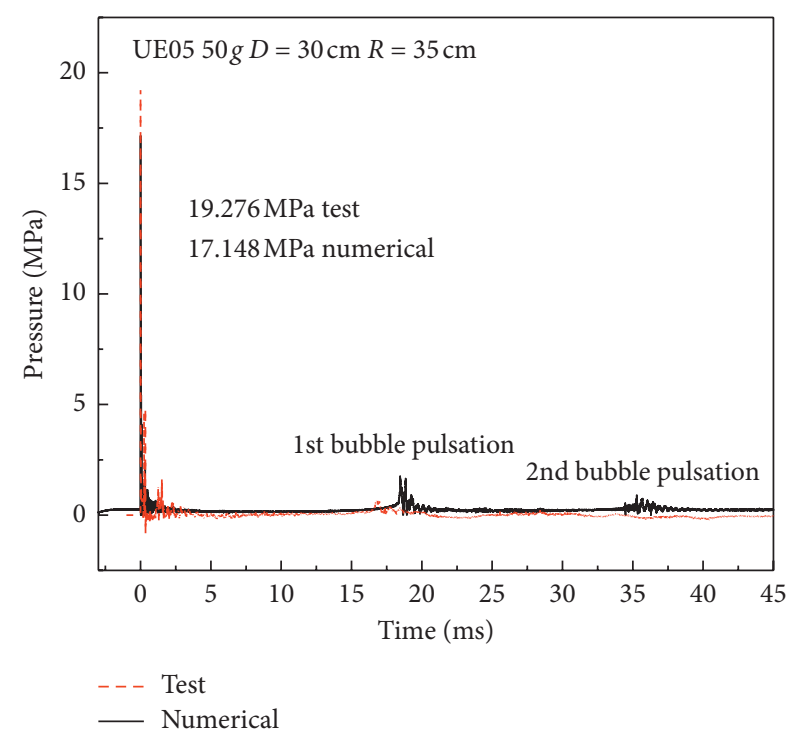

(d)

FIGURE 4: Comparison of experimental results and numerical simulation results of water pressure. (a) UE01. (b) UE02. (c) UE03. (d) UE05.

In addition to characteristic parameters, such as shock wave peak pressure and bubble pulsation period, the radius change in bubble pulsation is also a characteristic of dynamic loads under different accelerations. Figure 6 shows the comparison between the experimental results and the numerical simulation of the change in bubble radius in working condition UE01 $(G=20 \mathrm{~g})$.
In the bubble pulsation process, the numerical simulation results of the radius time history curve are close to the experimental results. However, because the numerical model cannot reflect all the real conditions in the experiment, the minimum radius of bubble obtained by numerical simulation is smaller than the experimental results, and the time is slightly delayed. However, in the whole bubble pulsation 


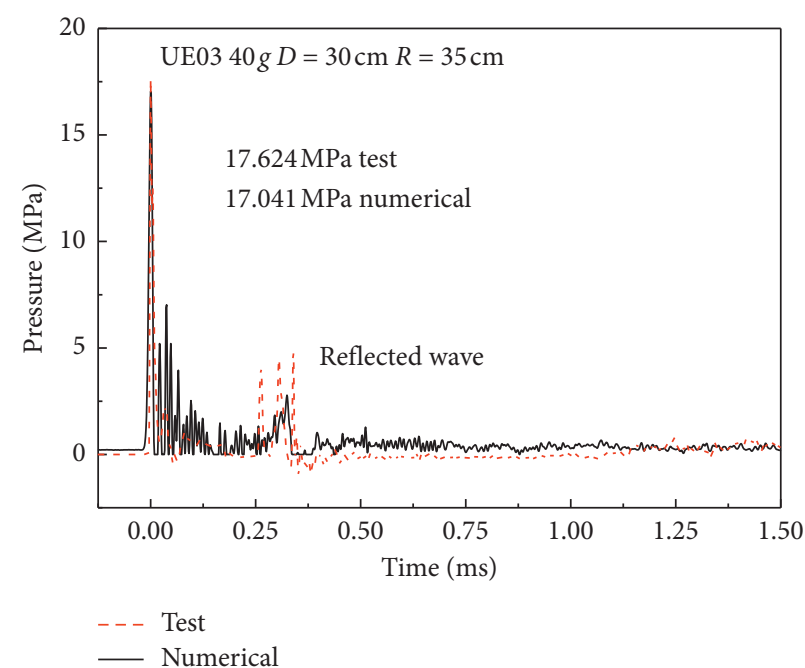

(a)

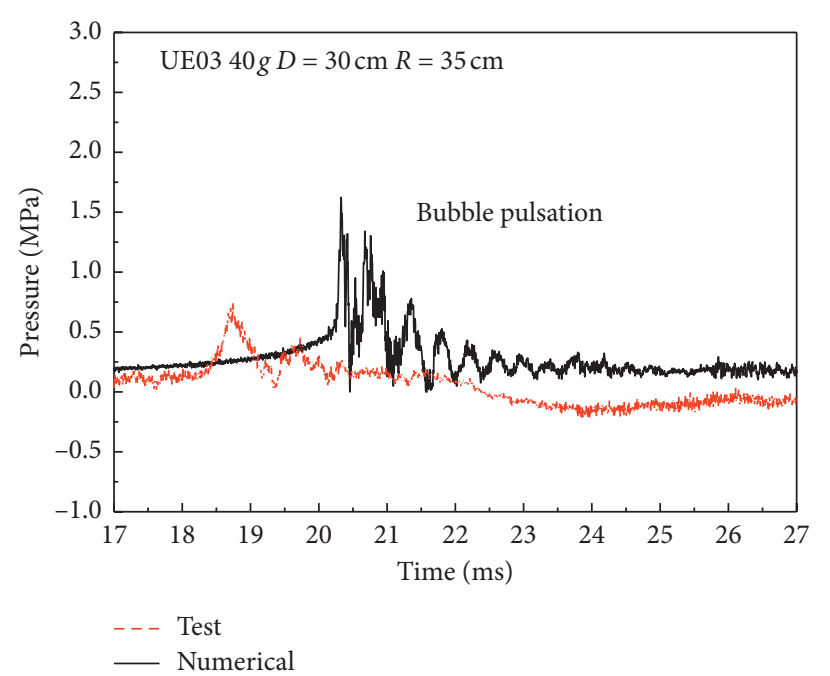

(b)

FIGURE 5: Comparison details of shock wave and bubble pulsation in UE03 working condition. (a) Pressure comparison in the shock wave stage. (b) Pressure comparison during bubble pulsation.

process, the variation trend of bubble radius and maximum radius obtained by numerical simulation are similar to those in the experimental results.

The dynamic process of underwater explosion under different acceleration conditions is reflected in the numerical simulation, whether it is the pressure time history curve or the change in bubble pulsation radius.

4.2. Dynamic Response of Steel Plate. In the numerical model, the fluid-structure coupling algorithm is used to transfer the load between the steel plate and the water. The steel plates in underwater explosions under different working conditions are still in the elastic stage, and the strain of different parts of the steel plate can describe the overall dynamic response of the steel plate. Taking UE01 $(G=20 \mathrm{~g})$ working condition as an example, the strain at 4-3 at the back water surface of the steel plate is shown in Figure 7, and the strain at 3-2 at the back water surface of the steel plate is shown in Figure 8 .

The steel plate is supported by the concrete support, the contact between them and the load transfer are complex, and the restraint conditions of the steel plate are also complicated. The numerical model established in this paper defines the contact between the steel plate and the concrete as surface-to-surface contact and directly fixes the back of the concrete support, which is different from the actual situation in the experiment, and the numerical model is a symmetrical modeling. The 4-3 measuring point is located on the symmetrical axis, and the strain oscillation after shock wave action is less obvious. In Figures 7 and 8, the oscillation trend of the strain obtained by numerical simulation between shock wave and bubble pulsation is different from the experimental results. The oscillation of the numerical simulation is smaller than the experimental results, which is largely affected by the steel plate constraint. The numerical simulation results are close to the experimental results in terms of strain trend and strain size. Although the bubble pulsation is much smaller than the peak pressure of shock wave, it still causes a large deformation of the structure, and the degree of deformation is no less than the effect of the shock wave on the structure. The strain recovery of the steel plate after shock wave action and bubble pulse action also proves that the steel plate is still in the stage of elastic deformation during the test.

The test is carried out in a closed cabin. After an underwater explosion occurs, the detonation product expands and pushes away the surrounding water. The detonation products will shrink faster because the water is constrained by the test bulkhead and the water's compressibility is small. In the numerical simulation, to reduce the influence of boundary reflection, the water boundary is set as a nonreflective boundary, which has pushed back the arrival time of bubble pulsation to a certain extent. Therefore, the bubble pulsation time obtained by the numerical simulation in Figures 7 and 8 is smaller than test results.

\section{Analysis}

5.1. Analysis of Similarity Law of Underwater Explosion. The centrifuge test aims to simulate the prototype test by applying a certain multiple of acceleration to the model. Table 6 shows the dimensions of the prototype test that corresponds to four different acceleration conditions. Among them, $W_{m}$ is the charge quantity of the scaled test, $W_{p}$ is the charge quantity of the prototype model, $D_{p}, L_{p}$, and $R_{p}$ are the position parameters of the water charge, which are the same as in Table 1, and Width $h_{p}$ and Height $t_{p}$ are the steel plate sizes of the prototype model, respectively.

The prototype underwater explosion model is established according to the model parameters in Table 6, and the same material parameters and environment settings are adopted as the centrifuge test model. When comparing the results of the prototype underwater explosion model with the centrifuge test results, the influence of the similarity rate 


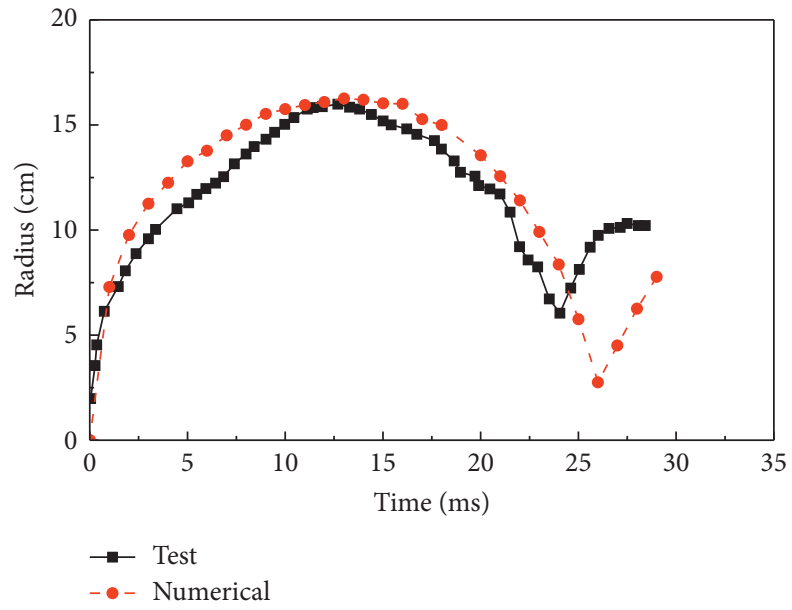

FIgURE 6: Comparison of experimental results and numerical simulation of the bubble radius time history curve (UE01).

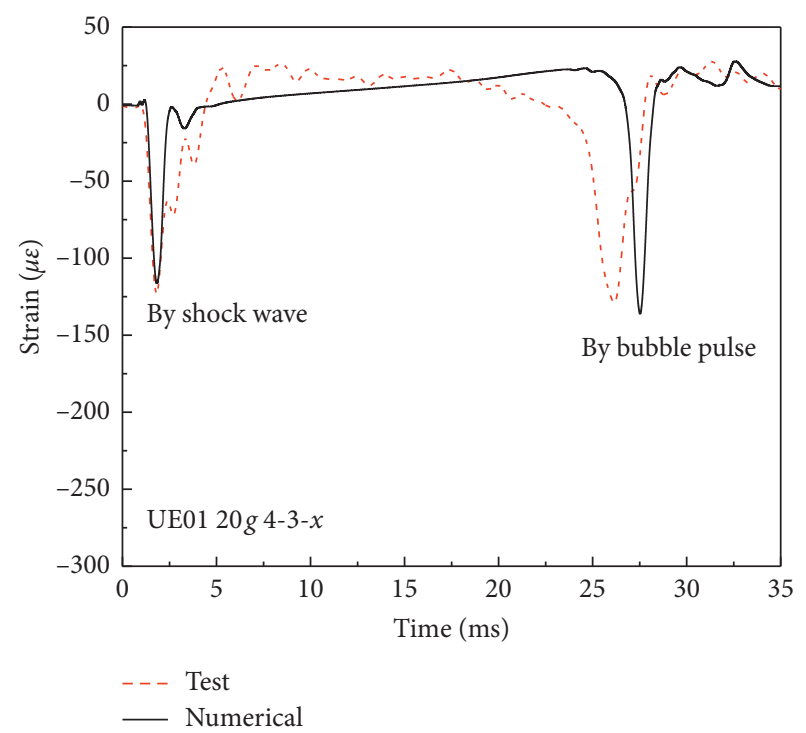

(a)

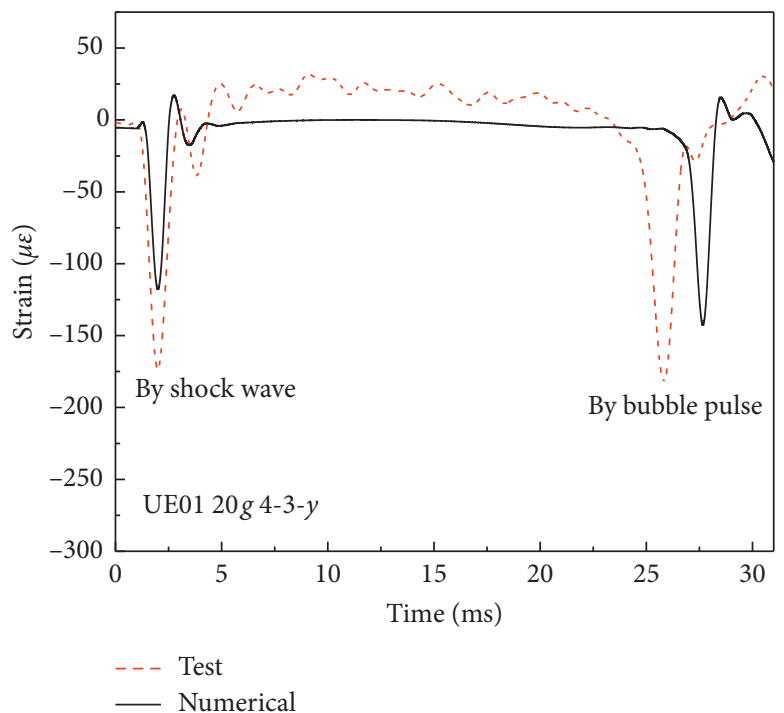

(b)

Figure 7: Comparison of test results and numerical simulation results of strain at 4-3 in UE01. (a) 4-3-x. (b) 4-3-y.

should be considered. According to the dimensional analysis in Table 2, pressure does not change during the scaling process, but the time parameter should change correspondingly to the scaling factor.

The time in the calculation results of the prototype model is reduced by the corresponding multiple and then compared with the centrifuge test results. Figures 9(a) and 9(b) show the comparison of the water pressure under working condition UE01 $(\lambda=1 / 20)$ and working condition UE05 $(\lambda=1 / 50)$, respectively. The results of centrifuge test and centrifuge simulation are very close to the scaled pressure time history curve of the prototype model, and shock wave peak pressure and bubble pulsation time have no significant differences. Taking UE01 working condition as an example, Figure 10 shows the details of pressure comparison in water. The attenuation of shock wave and bubble pulsation are well reflected in the simulation. Due to the setting of the surrounding environment, the simulated bubble pulsation is slightly different from the experimental results. The obvious reflection exists after the shock wave was measured by the experiment, but the nonreflection boundary is adopted in the numerical simulation. Thus, the reflection is not obvious in the numerical simulation. In general, the simulation results of the centrifuge test fit well with the simulation results of the prototype model, and the comparison between them fully shows the effectiveness of the similarity law in water pressure propagation.

\subsection{Similarity Analysis of Steel Plate Subjected to Underwater} Explosion. Based on the analysis of the load similarity ratio of underwater explosion, the dynamic response of the steel plate in underwater explosion with different accelerations can be studied further. First, verify whether the deformation 


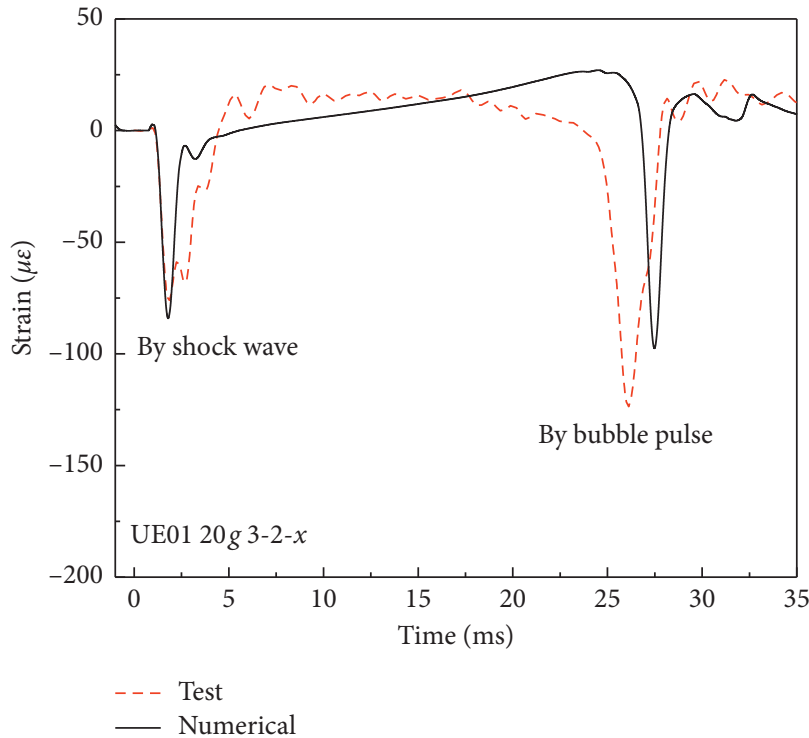

(a)

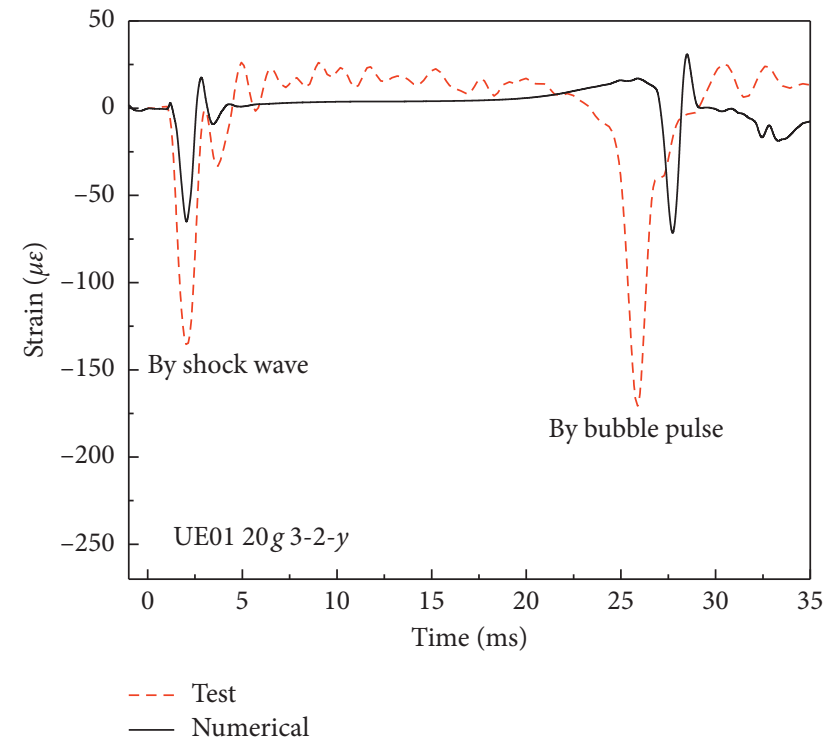

(b)

FIgURE 8: Comparison of test results and numerical simulation results of strain at 3-2 in UE01. (a) 3-2-x. (b) 3-2-y.

Table 6: Prototype underwater explosion test parameters corresponding to different centrifuge test conditions.

\begin{tabular}{lcccccccc}
\hline No. & $G$ & $W_{m}(\mathrm{~g})$ & $W_{p}(\mathrm{~kg})$ & $D_{p}(\mathrm{~m})$ & $L_{p}(\mathrm{~m})$ & $R_{p}(\mathrm{~m})$ & Width $_{p}(\mathrm{~m})$ & Height $_{p}(\mathrm{~m})$ \\
\hline UE01 & $20 \mathrm{~g}$ & 1.612 & 12.90 & 6 & 6 & 7 & 12 & 14 \\
UE02 & $30 \mathrm{~g}$ & 1.613 & 43.55 & 9 & 9 & 10.5 & 21 \\
UE03 & $40 \mathrm{~g}$ & 1.620 & 103.68 & 12 & 12 & 14 & 24 \\
UE05 & $50 \mathrm{~g}$ & 1.640 & 205.0 & 15 & 15 & 17.5 & 30 & 35 \\
\hline
\end{tabular}

of the steel plate subjected to hydrostatic pressure before detonation conforms to the law of similarity. Taking the working condition UE01 and its corresponding prototype model as an example, Figure 11 shows the strain distribution nephogram (strain perpendicular to the plate direction) of the two steel plates under hydrostatic pressure. The strain peak value of the steel plate after the additional acceleration of the centrifuge is close to that of the steel plate in the prototype model, and the strain range is similar. The deformation is mainly concentrated in the area directly opposite to the blasting center in the middle and diffuses outward in a circular shape. The reason is that the left and right sides and the bottom of the steel plate are constrained by concrete; hence, no large deformation is observed near the edge.

The stress of the steel plate under hydrostatic pressure in the two models conforms to the law of similarity. The prototype model is established according to the model parameters in Table 6. Taking $G=20 \mathrm{~g}$ and $G=50 \mathrm{~g}$ as examples, Figure 12 shows the displacement comparison of the back water surface of the steel plate under the action of shock wave under different acceleration conditions, where Figure 12(a) is the displacement comparison between UE01 (1.612 g TNT; $G=20 \mathrm{~g}$ ) and the corresponding prototype model $(12.90 \mathrm{~kg}$ TNT; $G=1 \mathrm{~g})$, in which the steel plate is expanded from $60 \mathrm{~cm} \times 70 \mathrm{~cm}$ to $12 \mathrm{~m} \times 14 \mathrm{~m}$ according to the similarity law, and the coordinates of $X$ and $Y$ directions are also expanded by 20 times. Similarly, Figure 12(b) is the displacement comparison between UE05 (1.64 g TNT; $G=50 \mathrm{~g})$ and the corresponding prototype model $(205.0 \mathrm{~kg}$ TNT; $G=1 \mathrm{~g}$ ), and the size of the steel plate is expanded by 50 times. Figure 12 presents that when the steel plate is in the elastic range, the displacement under the action of underwater explosion follows the similarity law.

Besides the deformation of the steel plate under the action of shock wave, the strain change of the steel plate under the action of shock wave and bubble pulsation can verify whether the steel plate conforms to the similarity law. Taking the 4-3 position where the back surface of the steel plate is facing the explosion center as an example, Figure 13 shows the strain response of the steel plate in UE01 and the corresponding prototype model under the action of an underwater explosion. The black dashed line in the figure is the strain curve measured by the UE01 test, the black solid line is the strain curve calculated by the scaled-down numerical model, and the red line is the strain response of the steel plate in the prototype model. The prototype model and scaled model share the number axis of strain. The time axis of the prototype model is the red one at the top, and the time axis of the scale model is the black one at the bottom. The 


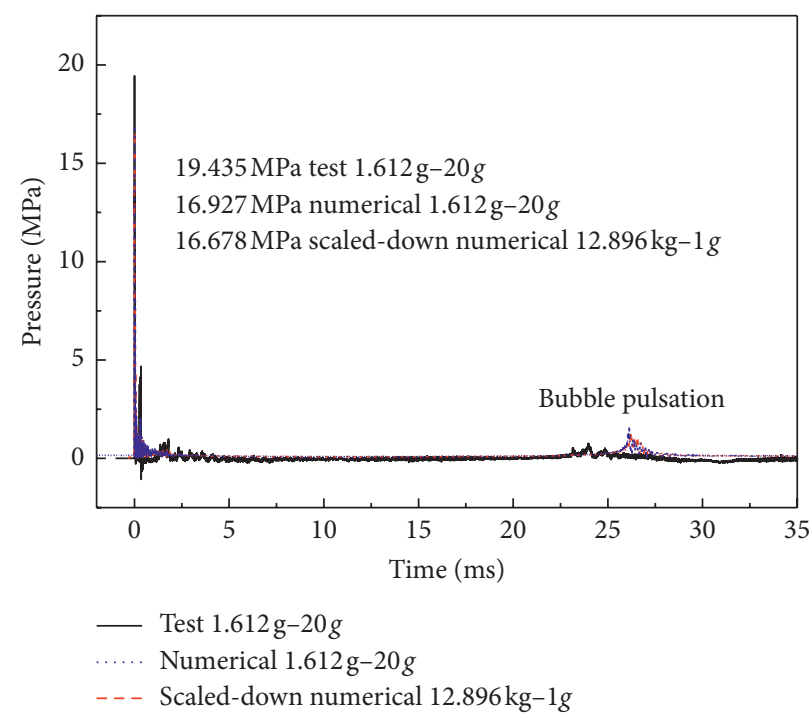

(a)

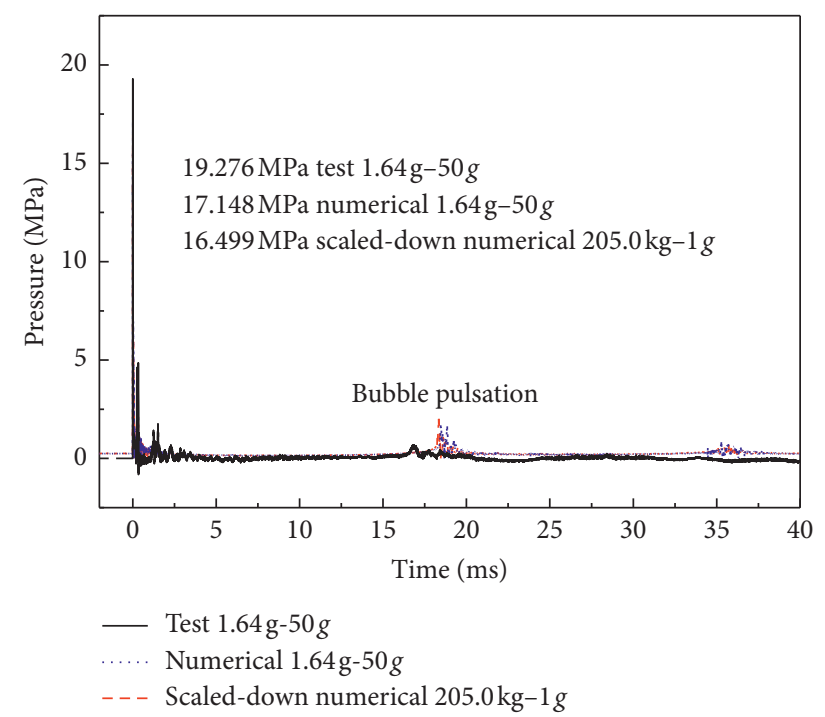

(b)

FIGURE 9: Comparison of water pressure between centrifuge test, prototype numerical simulation, and centrifuge test numerical simulation. (a) UE01. (b) UE05.

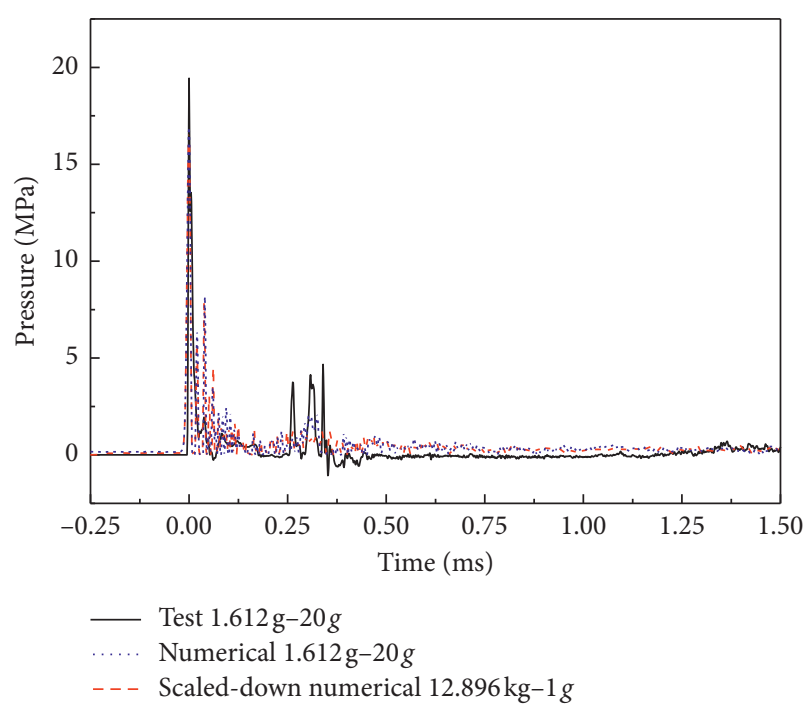

(a)

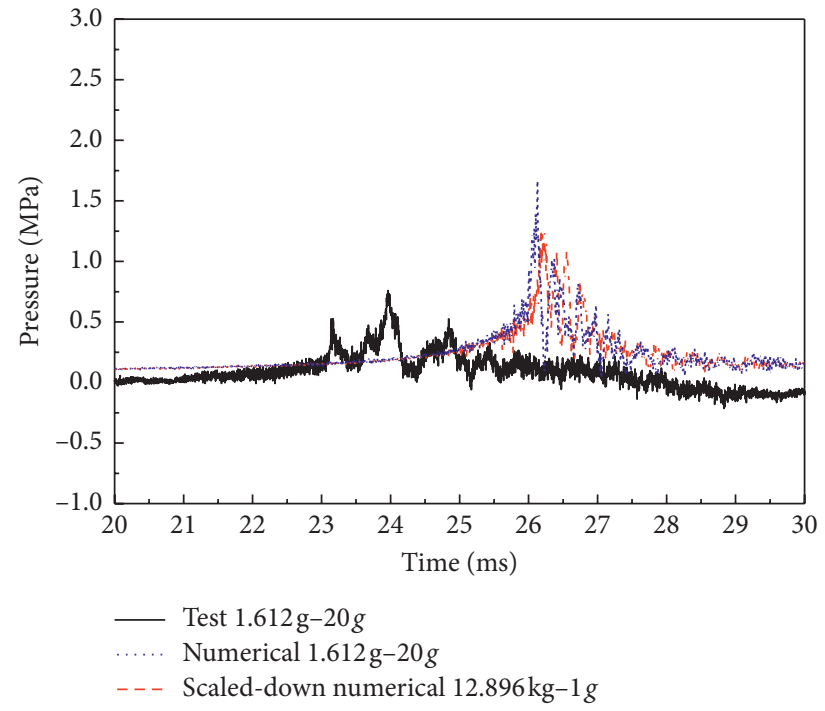

(b)

Figure 10: Comparison details of water pressure. (a) Shock wave. (b) Bubble pulsation.

time axis of the prototype model is 20 times larger than that of the scale model, which is exactly the same as the scale factor.

Figure 13 illustrates that the strain curve of the prototype model fits well with the scaled model. The strain values of the scaled model in Figure 13(a) are slightly different from those of the prototype model, but in general, the change trend of the strain is similar. The strain curves of 4-3-y in Figure 13(b) are almost coincident under the action of shock wave. The similarity law is well reflected in the response of the steel plate to underwater explosion. 


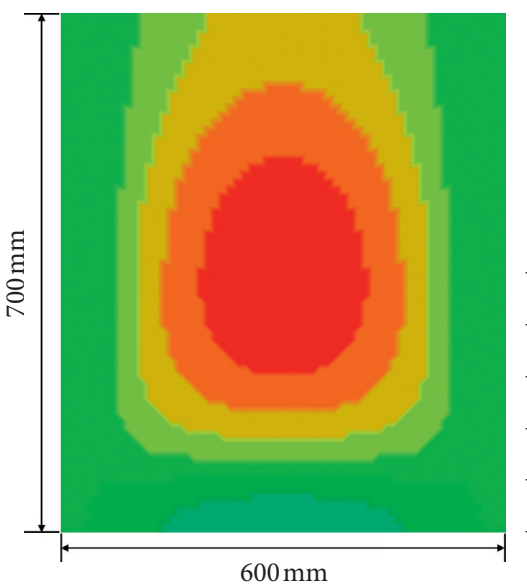

(a)
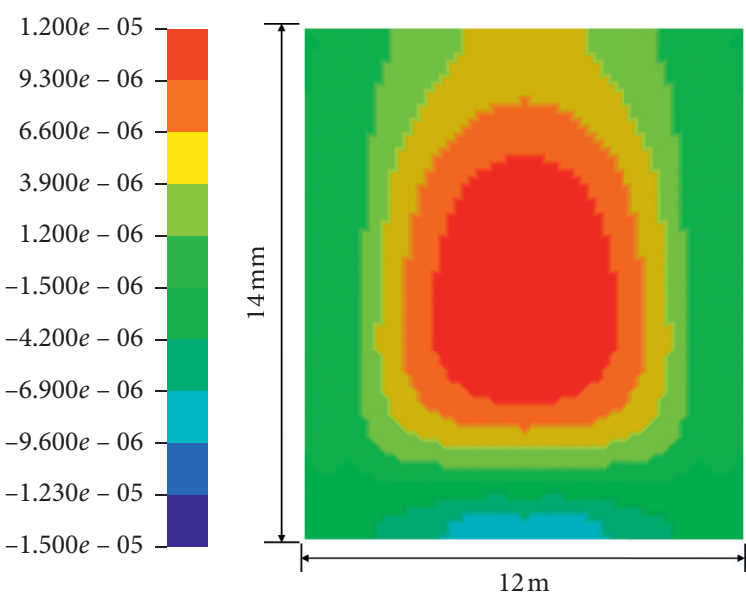

(b)

FIGURE 11: Strain comparison between UE01 and prototype model of the steel plate facing the water surface after being subjected to hydrostatic pressure. (a) Strain distribution of the steel plate facing the water surface in UE01. (b) Strain distribution of the steel plate facing the water surface in an underwater explosion of $12.896 \mathrm{~kg}$ TNT at $(\mathrm{G})=1(\mathrm{~g})$.
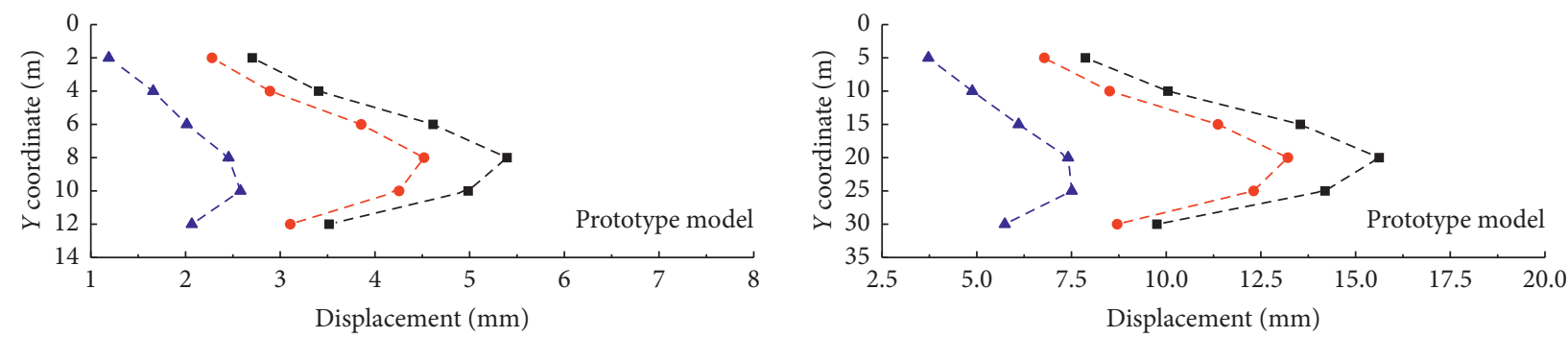

- - Numerical $12.90 \mathrm{~kg}-1 \mathrm{gX}=6 \mathrm{~m}$

- - Numerical $12.90 \mathrm{~kg}-1 \mathrm{gX}=4 \mathrm{~m}$

_. - Numerical $12.90 \mathrm{~kg}-1 \mathrm{gX}=2 \mathrm{~m}$

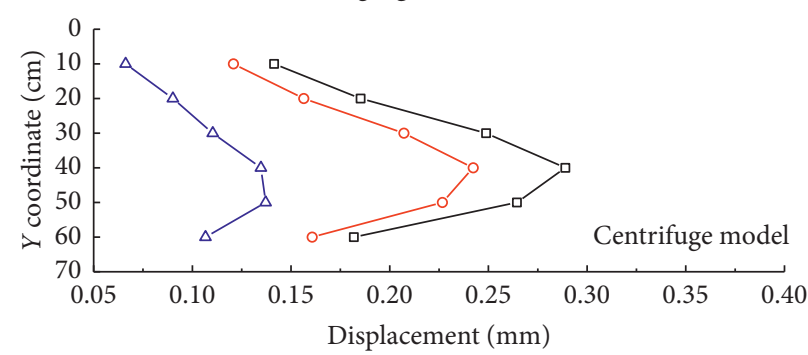

- - Numerical $205.0 \mathrm{~kg}-1 \mathrm{gX}=15 \mathrm{~m}$

- - Numerical 205.0kg-1 $g \mathrm{X}=10 \mathrm{~m}$

_ - - Numerical $205.0 \mathrm{~kg}-1 \mathrm{gX}=5 \mathrm{~m}$

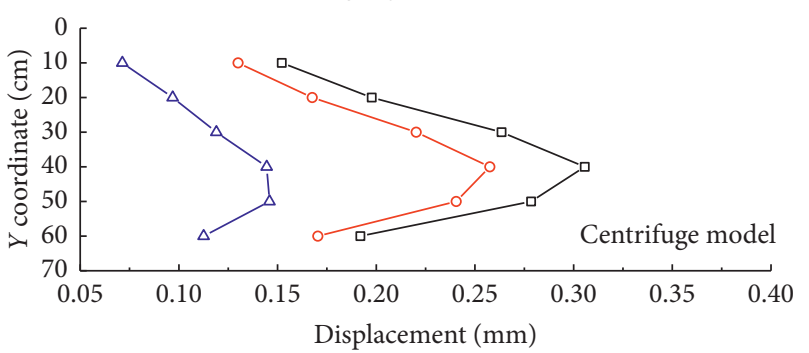

- - Numerical $1.612 \mathrm{~kg}-20 \mathrm{~g} X=30 \mathrm{~m}$

- - Numerical $1.64 \mathrm{~kg}-50 \mathrm{~g} X=30 \mathrm{~m}$

-o- Numerical $1.64 \mathrm{~kg}-50 \mathrm{gX}=20 \mathrm{~m}$

$-\circ-$ Numerical $1.612 \mathrm{~kg}-20 \mathrm{gX}=20 \mathrm{~m}$
$-\Delta-$ Numerical $1.612 \mathrm{~kg}-20 \mathrm{gX}=10 \mathrm{~m}$

$-\Delta-$ Numerical $1.64 \mathrm{~kg}-50 \mathrm{~g} X=10 \mathrm{~m}$

(a)

(b)

FIGURE 12: Comparison of displacement of the steel plate back surface between the scale model and prototype model of the centrifuge. (a) $(\mathrm{G})=20$ g. (b) $(\mathrm{G})=50 \mathrm{~g}$. 


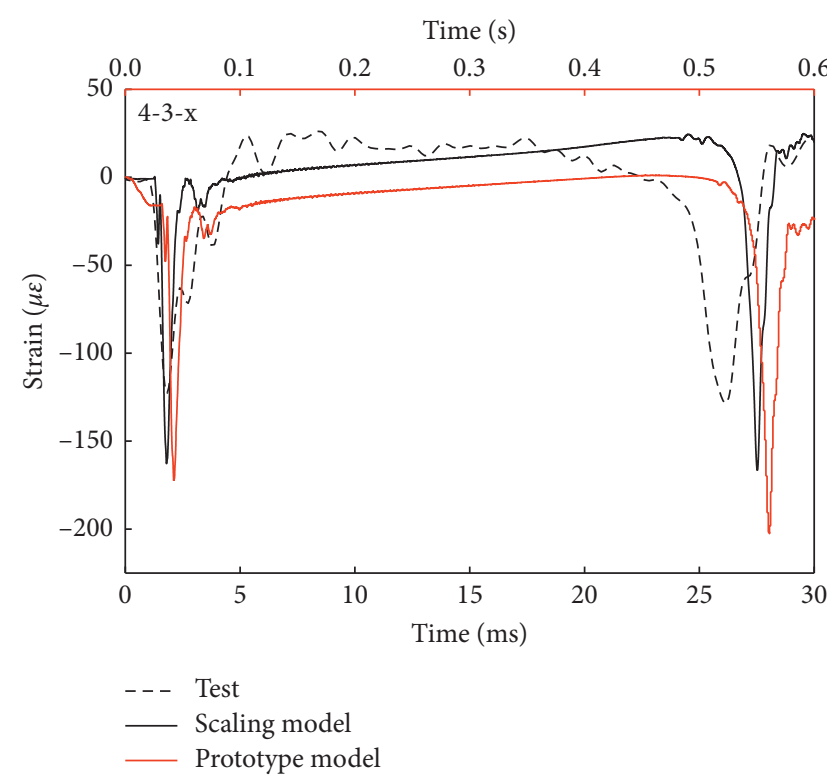

(a)

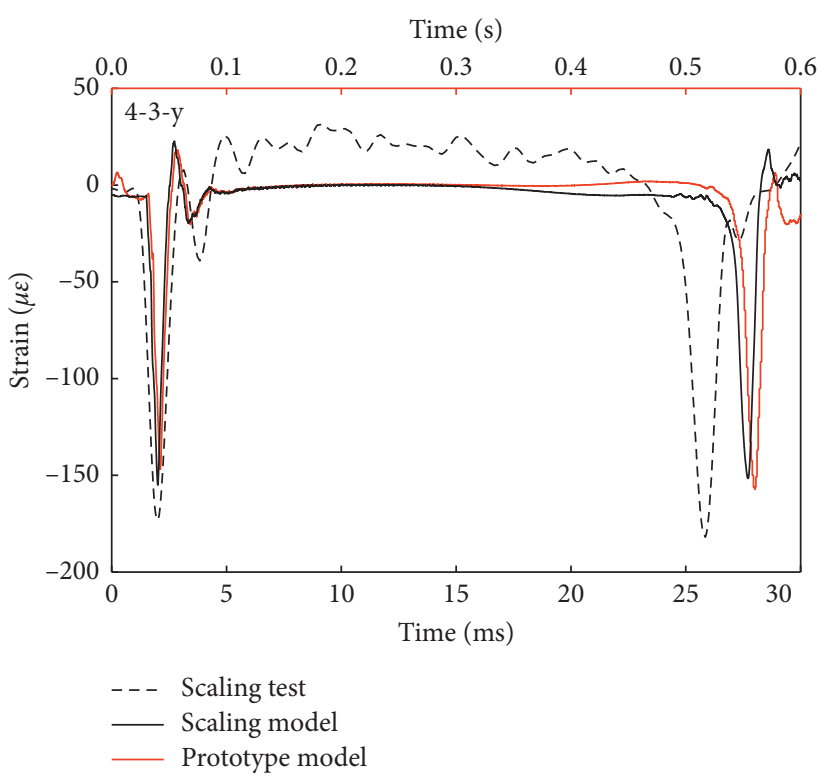

(b)

FIGURE 13: Strain comparison of the steel plate in the scale-down test, scale-down model, and corresponding prototype model. (a) 4-3-x. (b) 4-3-y.

\section{Conclusion}

In this paper, the numerical model of the steel plate in underwater explosion of the centrifuge is established, and the reliability of the numerical model is preliminarily verified by comparing with the time history curve of pressure in water and the strain curve of the steel plate measured by the experiment. The centrifuge scale test aims to simulate the dynamic mechanical test of the prototype by applying certain acceleration. Corresponding to different acceleration conditions, this paper establishes the corresponding enlarged size prototype model and further explores the feasibility of the centrifuge scale-down test in studying the dynamic response of the structure under the action of underwater explosion. This paper draws the following conclusions through the comparative analysis of numerical simulation and experiment:

(1) By selecting appropriate material parameters and modeling method, the dynamic behavior of underwater explosion and the dynamic response of the steel plate under underwater explosion can be simulated well, which is suitable for the case of $G=n g(n>1)$ and $G=1 \mathrm{~g}$.

(2) In the centrifuge scale test, the deformation of the steel plate is mainly caused by shock wave and bubble pulsation. The deformation of the steel plate back surface caused by bubble pulsation is close to that caused by shock wave, which is proven by the numerical model and test.

(3) In the centrifuge underwater explosion model, the shock wave load is not greatly affected by the acceleration, and the propagation of shock wave in water still follows the same law of shock wave peak under the same proportion of explosion distance. The acceleration of the centrifuge test mainly changes the bubble pulsation of underwater explosion. The calculation results of corresponding prototype models established for centrifuge tests under different acceleration conditions are also shown in this point. The time parameters of the prototype model can be reduced by the corresponding multiple in the time history of the pressure in water, which can be used to fit the test results of the centrifuge. In shock wave propagation and bubble pulsation, the relationship between the prototype model and centrifuge test follows the scaling relationship.

(4) Through the analysis and comparison of the displacement and strain processes of the back water surface when the steel plate is subjected to the shock wave, the scaling condition of the centrifuge and the dynamic response of the steel plate in the prototype model follow the scaling relationship. Scaling is not only meaningful in the study of water load but also plays an important role in the study of the structural response.

(5) In the working conditions studied in this paper, whether the centrifuge test and prototype model, the section of the steel plate is a regular rectangle, the steel is in the stage of linear elasticity, and the steel plate structure has good similarity law between the centrifuge scale working condition and prototype model, which is inseparable from its own constitutive characteristics. For nonlinear dynamic constitutive concrete and hydraulic structures with irregular cross section, the shrinkage ratio of concrete subjected to underwater explosion must be explored further. 


\section{Data Availability}

The research cited experimental data from papers by $\mathrm{J}$. $\mathrm{Hu}$ and Y. Long et al. The experimental data query website is http://www.geoeng.iwhr.com/ytgcyjs/czy/bpsj/index.html.

\section{Conflicts of Interest}

The authors declare that they have no conflicts of interest.

\section{Acknowledgments}

The authors would like to appreciate the financial supports from the National Natural Science Foundation of China (Grant nos. 12032004 and 11872157). The authors also thank $\mathrm{Hu}$ Jing at China Institute of Water Resources and $\mathrm{Hy}-$ dropower for valuable suggestions and kind help.

\section{References}

[1] 1948 Cole, Underwater explosions.

[2] T. E. Farley and H. G. Snay, "Unclassified data from classified source," in Explosion Effects and Properties Part II: Explosion Effects in Water, M. M. Swisdak, Ed., NSWC/WOL TR 76-116, NSWC, Maryland, 1978.

[3] B. Zamyshlyayev and S. Yakovlev Yu, Dynamic Loads in Underwater Explosion, Naval Intelligence Support Center, Washington, DC, USA, 1973.

[4] T. L. Geers and K. S. Hunter, "An integrated wave-effects model for an underwater explosion bubble," Journal of the Acoustical Society of America, vol. 111, no. 4, pp. 1584-1601, 2002.

[5] J. P. Slifko, "Pressure-pulse characteristics of deep explosion as functions of depth and range," Tech. Rep. AD-661804, U. S. Naval Ordinance Laboratory, White Oak, Md., 1967.

[6] X. L. Yao, Y. Wang, and A. M. Zhang, Underwater Explosion Bubble Dynamics, Harbin Engineering University Press, Harbin, China, 2011.

[7] A. M. Zhang, W. B. Wu, Y. L. Liu, and Q. X. Wang, "Nonlinear interaction between underwater explosion bubble and structure based on fully coupled model," Physics of Fluids, vol. 29, no. 8, Article ID 082111, 2017.

[8] C. F. Hung and J. J. Hwangfu, "Experimental study of the behaviour of mini-charge underwater explosion bubbles near different boundaries," Journal of Fluid Mechanics, vol. 651, pp. 55-80, 2010.

[9] J. Hu, Z. Chen, X. Zhang et al., "Underwater explosion in centrifuge part I: validation and calibration of scaling laws," Science China Technological Sciences, vol. 60, no. 11, pp. 1638-1657, 2017.

[10] Y. Long, H. Zhou, X. Liang et al., "Underwater explosion in centrifuge Part II: dynamic responses of defensive steel plate," Science China Technological Sciences, vol. 60, no. 12, pp. 1941-1957, 2017.

[11] G. Song, Z. Y. Zu, and Y. Long, "Experimental and numerical investigation of the centrifugal model for underwater explosion shock wave and bubble pulsation," Ocean Engineering, vol. 142, pp. 523-531, 2017.

[12] H. G. Snay, Migration of Explosion Bubbles in a Rotating Test Tank, Naval Ordnance Lab Oak MD, Maryland, 1962.

[13] R. S. Price, W. G. Zuke, and C. Infosino, A Study of Underwater Explosions in a High Gravity Tank, Naval Ordnance Lab Oak MD, Maryland, 1964.
[14] Q. Wang, S. Liu, and H. Lou, "Calibration of numerical simulation methods for underwater explosion with centrifugal tests," Shock and Vibration, vol. 2019, Article ID 2670836, 19 pages, 2019.

[15] Z. Wang, W. Gu, and J. Liu, "Experimental study on peak pressure of shock waves in quasi-shallow water," Mathematical Problems in Engineering, vol. 2015, Article ID 702178, 13 pages, 2015.

[16] G. Zhang, P. Wang, M. Zhao, X. Du, and X. Zhao, "Seismic structure-water- sediment- rock interaction model and its application to immersed tunnel analysis under obliquely incident earthquake," Tunnelling and Underground Space Technology, vol. 109, Article ID 103758, 2021.

[17] P. Wang, Y. Xu, and X. Zhang, "A substructure method for seismic responses of offshore wind turbine considering nonlinear pile-soil dynamic interaction-Science Direct," Soil Dynamics and Earthquake Engineering, vol. 144, Article ID 106684, 2021.

[18] P. Wang, Z. Zhang, Q. Yan, and C. Zhang, “A substructure method for the transient response of vertical cylinders subjected to shock wave of underwater explosion," Ocean Engineering, vol. 218, Article ID 108128, 2020.

[19] J. R. Blake and D. C. Gibson, "Cavitation bubbles near boundaries," Annual Review of Fluid Mechanics, vol. 19, no. 1, pp. 99-123, 1987.

[20] E. Klaseboer, K. C. Hung, C. W. Wang, and B. C. Khoo, "Experimental and numerical investigation of the dynamics of an underwater explosion bubble near a resilient/rigid structure," Journal of Fluid Mechanics, vol. 53, no. 7, pp. 387-413, 2005.

[21] Y. L. Liu, Q. X. Wang, S. P. Wang, and A. M. Zhang, "The motion of a 3D toroidal bubble and its interaction with a free surface near an inclined boundary," Physics of Fluids, vol. 28, no. 12, Article ID 122101, 2016.

[22] A. Pearson, E. Cox, J. R. Blake, and S. R. Otto, "Bubble interactions near a free surface," Engineering Analysis with Boundary Elements, vol. 28, no. 4, pp. 295-313, 2004.

[23] P. Cui, A. M. Zhang, and S. P. Wang, "Small-charge underwater explosion bubble experiments under various boundary conditions," Physics of Fluids, vol. 28, no. 11, Article ID 117103, 2016.

[24] W. Xiao, A. M. Zhang, and S. P. Wang, "Investigation of bubble dynamics of underwater explosion based on improved compressible numerical model," Applied Ocean Research, vol. 59, pp. 472-482, 2016.

[25] L. Liu, R. Guo, K. Gao, and M. Zeng, "Full-field peak pressure prediction of shock waves from underwater explosion of cylindrical charges," Propellants, Explosives, Pyrotechnics, vol. 42, no. 8, pp. 912-920, 2017.

[26] F. R. Ming, A. M. Zhang, Y. Z. Xue, and S. P. Wang, "Damage characteristics of ship structures subjected to shockwaves of underwater contact explosions," Ocean Engineering, vol. 117, pp. 359-382, 2016.

[27] Y. Liu, A.-M. Zhang, Z. Tian, and S. Wang, "Investigation of free-field underwater explosion with Eulerian finite element method," Ocean Engineering, vol. 166, pp. 182-190, 2018.

[28] L. Hai and X. Ren, "Computational investigation on damage of reinforced concrete slab subjected to underwater explosion," Ocean Engineering, vol. 195, Article ID 106671, 2020.

[29] Dl/T 5102-2013, Technical Specification for Geotechnical Centrifugal Model Test, National Energy Administration, Beijing, China, 2013.

[30] G. Wang, Y. Wang, W. Lu, W. Zhou, M. Chen, and P. Yan, "On the determination of the mesh size for numerical 
simulations of shock wave propagation in near field underwater explosion," Applied Ocean Research, vol. 59, pp. 1-9, 2016.

[31] Y. S. Shin, M. Lee, K. Y. Lam, and K. S. Yeo, "Modeling mitigation effects of watershield on shock waves," Shock and Vibration, vol. 5, no. 4, pp. 225-234, 1998.

[32] K. G. Webster, "Investigation of close proximity underwater explosion effects on a ship-like structure using the multimaterial arbitrary Lagrangian Eulerian finite element method," Master thesis, Virginia Polytechnic Institute and State University, Blacksburg, Virginia, 2007. 